\title{
Uhl anomaly
}

INSERM

\section{Source}

INSERM. (1999). Orphanet: an online rare disease and orphan drug data base. Uhl anomaly. ORPHA:3403

Uhl anomaly is characterized by an almost complete absence of the myocardium in the right ventricle resulting in a thin walled nonfunctional right ventricle manifesting with cardiac arrhythmias and right ventricular failure. Cases of partial absence of right ventricular myocardium which remains asymptomatic or mildly symptomatic until adulthood have also been reported. Patients presenting with complete Uhl anomaly should be considered for cardiac transplantation. 